\title{
Erratum to: The management of ductal intraepithelial neoplasia (DIN): open controversies and guidelines of the Istituto Europeo di Oncologia (IEO), Milan, Italy
}

\author{
Gabriel Farante $\cdot$ Stefano Zurrida $\cdot$ Viviana Galimberti $\cdot$ \\ Paolo Veronesi · Giuseppe Curigliano • Alberto Luini · \\ Aron Goldhirsch $\cdot$ Umberto Veronesi
}

Published online: 21 September 2010

(C) Springer Science+Business Media, LLC. 2010

\section{Erratum to: Breast Cancer Res Treat \\ DOI 10.1007/s10549-010-1124-4}

Under section "Guidelines for systemic treatment" it should read

(a) ER-positive patients: premenopausal and postmenopausal patients receive low-dose tamoxifen $(20 \mathrm{mg} /$ week) or participate in the IBIS-2 trial, which has two arms: after quadrantectomy, Tamoxifen ( $20 \mathrm{mg}$ /day) versus Anastrazole (1 $\mathbf{~ m g / d a y ) ; ~ a f t e r ~ m a s t e c t o m y , ~ A n a s t r a z o l e ~ ( 1 ~} \mathbf{~ m g / d a y )}$ versus placebo.
Instead of

(a) ER-positive patients: premenopausal and postmenopausal patients receive low-dose tamoxifen ( $20 \mathrm{mg} / \mathrm{week}$ ) or participate in the IBIS-2 trial, which has two arms: after quadrantectomy, Tamoxifen $(20 \mathrm{mg} /$ day $)$ versus Anastrazole (100 mg/day); after mastectomy, Anastrazole $(\mathbf{1 0 0} \mathbf{~ m g} /$ day) versus placebo.

The online version of the original article can be found under doi:10.1007/s10549-010-1124-4.

G. Farante $(\bowtie) \cdot$ S. Zurrida · V. Galimberti · P. Veronesi ·

A. Luini

Division of Senology, European Institute of Oncology,

IEO, Via Ripamonti 435, 20141 Milan, Italy

e-mail: gabriel.farante@ieo.it

S. Zurrida · P. Veronesi - G. Curigliano · A. Goldhirsch

Department of Medicine, European Institute of Oncology,

IEO, Milan, Italy

S. Zurrida $\cdot$ P. Veronesi $\cdot$ U. Veronesi

Scientific Directorate of the European Institute of Oncology,

IEO, Milan, Italy

S. Zurrida $\cdot$ P. Veronesi

School of Medicine, University of Milan, Milan, Italy 